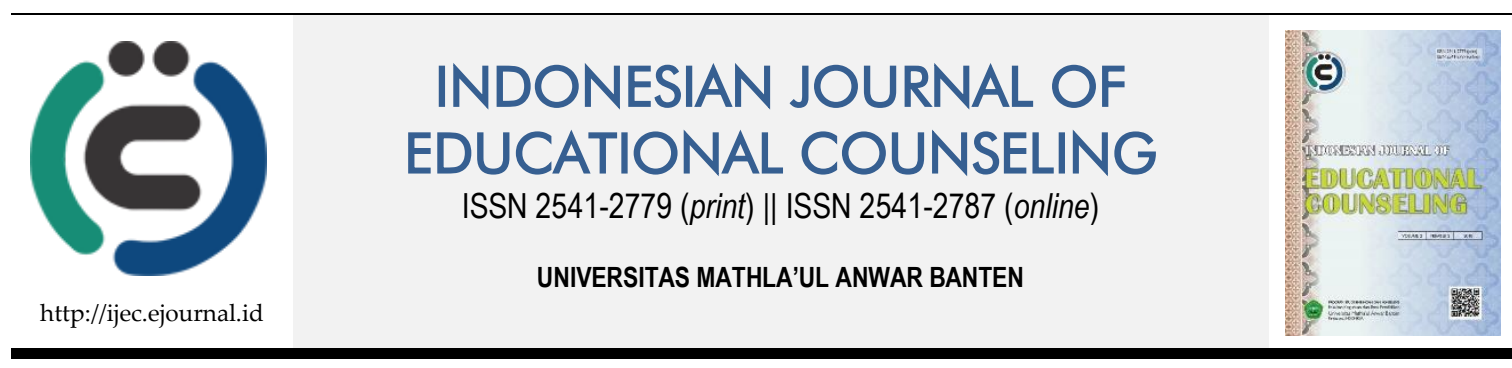

Research Based Article

\title{
Influence of Personality-Traits and Learning Styles on Distance Learners' Academic Performance in University of Cape Coast
}

\author{
John Ekow Laryea ${ }^{1}$ \\ 1 University of Cape Coast
}

\begin{tabular}{|c|c|}
\hline ARTICLE INFO & ABSTRACT \\
\hline $\begin{array}{l}\text { Article History: } \\
\text { Received 12.06.2018 } \\
\text { Received in revised } \\
\text { form 04.07.2018 } \\
\text { Accepted } 18.07 .2018 \\
\text { Available online } \\
21.07 .2018\end{array}$ & $\begin{array}{l}\text { The aims of the study was to investigate the influence of personality-traits and } \\
\text { learning styles on academic performance of University of Cape Coast (UCC) } \\
\text { distance learners, taking into consideration the moderating effects of academic } \\
\text { self-discipline and academic self-confidence. The correlational research design } \\
\text { was adopted. The sample was } 805 \text {, made up of } 10 \text { centre coordinators, } 763 \text { level } \\
200 \text { Diploma in Basic Education (DBE) students and } 32 \text { course tutors. The } \\
\text { stratified sampling procedure that makes use of the random number method of } \\
\text { simple random sampling technique was used to select all the respondents. } \\
\text { Questionnaire and interview-guide were the instruments used. The } \\
\text { quantitative data was analysed using both descriptive and inferential statistics, } \\
\text { while the qualitative data were analysed manually using the thematic } \\
\text { approach. The study revealed that openness to experience traits that students } \\
\text { demonstrate contributes more to their likelihood of obtaining high level } \\
\text { academic performance. Also, students prefer using read/write and visual } \\
\text { learning styles. Furthermore, students' personality-traits and learning styles } \\
\text { have significant influence on students' academic performance. However, this } \\
\text { influence becomes stronger indirectly through the moderating effect of } \\
\text { students' academic self-discipline and self-confidence. }\end{array}$ \\
\hline
\end{tabular}

Keywords: Distance Learners, Learning Styles, Personality-Traits, SelfConfidence, Self-Discipline.

\section{INTRODUCTION}

Globally, educators are concerned with methodologies that increase students' performance. Recognising that students are different and that teachers need to respond to these differences is not a new concept in education (Abidin et al., 2011). The introduction of multiple learning environments opens questions about effective course design based on students' individual differences. Given the financial benefits and possibility of enrolment

${ }^{1}$ Corresponding author’s address: College of Distance Education, University of Cape Coast, Ghana. Email: john.laryea@ucc.edu.gh. 
increases, it is not surprising that colleges and universities are off late offering more courses via distance education formats (Akrofi, 2010). This was as a result of the fact that universities in the country do accept the fact that their campuses are not large enough to accommodate the increasing number of senior high school grandaunts (Busari, 2017).

The distance education programme of College of Distance Education (CoDE), UCC is one of the solutions that the university has adopted to contain the capacity pressures that increasing registrations have on higher education in Ghana. CoDE of UCC was established to run Education, Business and Maths and Science programmes at diploma and degree levels, and has now incorporated master's programmes. Since its inception, the programme has run steadily to meet the purposes for which it was established (CoDE, UCC, 2017b).

However, academic performance of most of the learners of Diploma in Basic Education (DBE) programme has not been encouraging. Records show that first semester courses in 2011/2012 academic year, 1000 out of 2300 students representing 43.5 percent grades were below satisfactory, which is 1.50 in Introduction to Measurement and Evaluation (CoDE, UCC, 2017a). In Mathematics for Basic School Teachers, Methods of Teaching Basic School Science and Physical Education, 664 (28.9\%), 599 (26\%) and 466 (20.3\%) students also obtained grades less than 1.50 respectively. Recent evidence of this trend of students' low-performance shows that the majority (55.2\%) of DBE level 200 students' CGPAs were below satisfactory (CoDE, UCC, 2017b). This trend of performance appears not to be encouraging since the expectation of the college in every year, is to graduate the majority of its intake of students obtaining second class lower and above.

In view of the low-performance trend in the college, some interventions have been made by the Department of Quality Assurance and Enhancement (DQAE) of CoDE to avert the trend. Some of these interventions include: sharing end of semester examinations report findings with members of the top-management committee of $\mathrm{CoDE}$, monitoring the administration of quizzes and end of semester examinations, develop instruments for the assessment of course tutors in the various study centres by students and continuing reviewing and developing instruments for the monitoring of study centres (UCC, 2016). Notwithstanding all that, the trend still persists as it appears that more needs to be done.

Some of the several factors which relevant literature identifies to be responsible for academic performance include personality-traits and learning styles (Aragon, Johnson \& Shaik, 2012). In view of this, there has been a general argument among psychologists that failures of students cannot completely be attributed to poor instructional methods of teachers and lack of teaching and learning materials, but also to other factors which take account of students' negative application of personality-traits and ineffective learning styles (Irani, Telg, Scherler \& Harrington, 2012). This position has been confirmed by some other studies (Busari, 2017; Jannatul-Firdaos, 2014; Rimmerman, 2016) that some students on distance education programme lack good learning styles as well as effective study skills, leading to low-performance in school. This may imply that the predictor variables in question, when properly and effectively applied will help students to do selfevaluation, transform learning materials, set goals, seek information and keep records of work, and review notes or books which eventually lead to good academic performance among them.

In the Ghanaian context, studies (Koomson, 2006 \& Akrofi, 2010) on UCC distance learners, identified a combination of workload with academic work, family interference at home, church and other societal responsibilities, inability to organise well for quizzes and 
examinations, and lack of confidence which tends to concentrate on memorising facts to write examination, as some of the causes which militate against academic performance among learners of CoDE. As issues concerning the predicting variables, personality-traits and learning styles, have not yet received scholarly attention in any of the research works on students of CoDE. It has become of great concern to the researcher to investigate the predictability of personality-traits and learning styles on students' academic performance, considering the effects of both academic self-discipline and academic self-confidence as moderators, hence the study.

\section{Purpose and Hypothesis of the Study}

Generally, the study investigated the influence of personality-traits and learning styles on the academic performance of UCC distance learners, taking into consideration the moderating effects of academic self-discipline and academic self-confidence. The study therefore, hypothesised that:

$\mathrm{H}_{0}$ : Students' personality-traits and learning-styles do not have a strong direct influence on their academic performance.

$\mathrm{H}_{1}$ : Students' personality-traits and learning-styles have a strong direct influence on their academic performance.

\section{Significance of the Study}

The beneficiaries of the study will be all students of CoDE, UCC as well as distance learners in other institutions throughout the country. Perhaps the most important implication of research in these areas is the relationship between individual differences and performance outcomes. Designers and instructors of distance education may also benefit from the use of this research, by creating more effective learning environments specifically designed to accommodate a variety of individual differences. Again, it is envisaged that the findings of the study will contribute to the existing and related literature on distance learners' personality-traits and learning styles, used in the study to enhance academic performance among students, and generally in teaching. It is also envisaged, that the study will aid lecturers, course coordinators, course tutors and other stakeholders see the need to support students with the provision of relevant educational materials and some other supporting services that can facilitate their learning. The findings will further broaden professional and intellectual horizon of Counsellors and thereby sharpen their professional skills to enable them render effective counselling services to students to improve performance academically.

\section{Delimitation}

There are many constructs/variables which can serve as predictors of students' academic performance, but the study was delimited to personality-traits and learningstyles, taking into consideration the moderating effects of academic self-discipline and self-confidence. This is because some studies have already shown their predictability in academic performance of students from the western culture and not in the Ghanaian context, especially in CoDE, UCC, where the researcher's interest lies. Geographically, the study was delimited to all the regional study centres of CoDE, UCC and it covered only DBE students.

\section{Conceptual Framework}

The conceptual framework for this study was created using five main variables: personality-traits, learning style, academic self-discipline, academic self-confidence and 
academic performance. In relation to the predictor variables, the dimensions of personality-traits were adapted from the work of Golbert (as cited in Rimmerman, 2016) while that of learning styles were adapted from the work of Aragon et al. (2012). In relation to the moderators, the two variables considered were academic self-confidence and academic self-discipline, while students' academic performance was the criterion variable (See Figure 1).

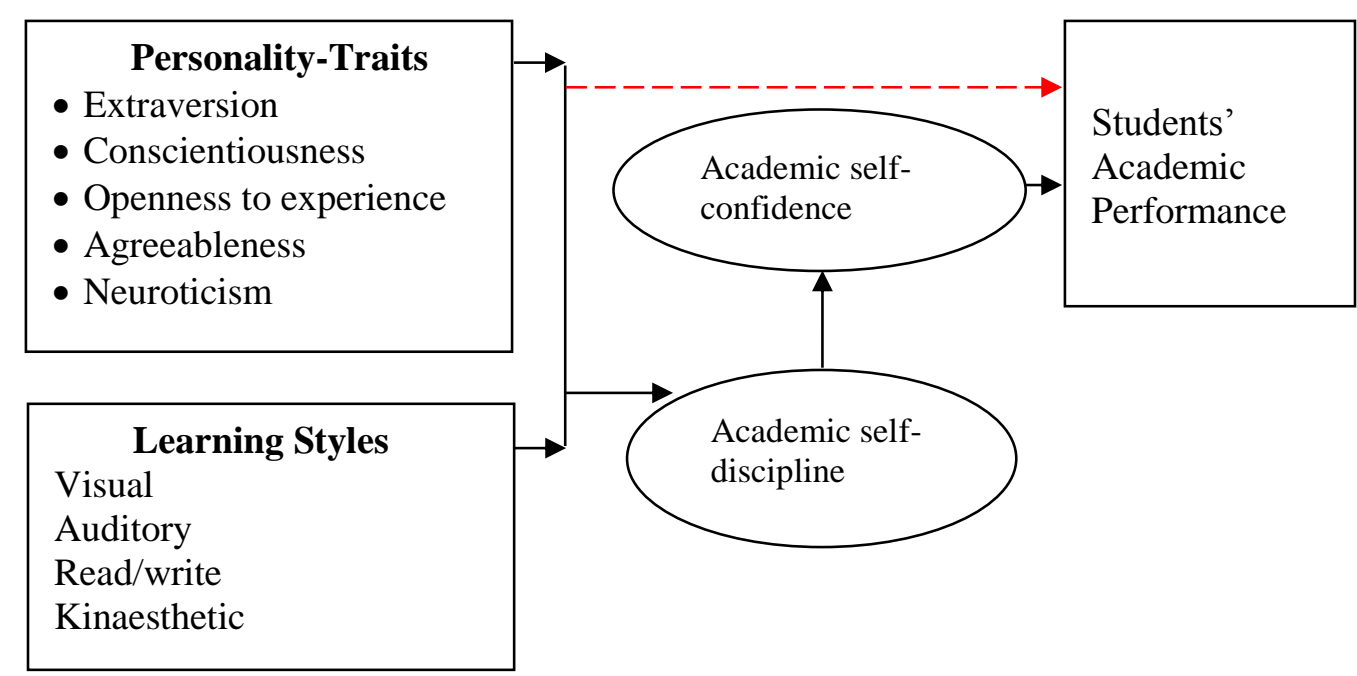

Figure 1. Model on the Predictability of Personality-Traits and Learning Styles on Distance Learners' Academic Performance

Source: Author's own construct, 2017

The point being established here is that if students perceive these variables in positive terms, it will help them in boosting their confidence level with regard to academic issues by first being academic self-disciplined. Therefore, enhancement of students' academic self-discipline through counselling will in turn make them more confident of themselves with regard to their academic work, which in the long run will also help improve their academic performance significantly. This means that students are to be assisted through counselling programmes to learn to be academically self-disciplined. Besides, they must also exert some level of effort in their academic work and be conscientious to develop academically. This will no doubt boost their academic work through which will also lead to significant increase in their academic performance.

\section{METHODS}

The study adopted the mixed method approach which makes use of both quantitative and qualitative approaches, and the correlational research design was considered as the most appropriate design to use. The population was made up of all students, offering Diploma in Basic Education at CoDE, UCC in the 2015/2016 academic year. They were 28602 in number (CoDE, UCC, 2017a). The sample size for the study was 805, made up of 10 centre coordinators, 763 level 200 DBE students and 32 course tutors. The sample size chosen was obtained based on the recommendations of Ary, Jacobs, Sorensen and Razavich (2010), who are of the view that a sample of five to ten percent of the accessible population is appropriate and meaningful representation for a survey study that is correlational in nature. Therefore, it was appropriate to sample 805 respondents representing 8.07 percent of the accessible population of 9976 . The stratified sampling 
procedure that makes use of the random number method of simple random sampling technique was used to select all the respondents and the participants after using the proportional sampling technique to sample 8.07 percent of the population, based on the three strata: students, course tutors and centre coordinators. In all, 805 respondents were selected for the study. Two instruments, questionnaire and interview guide, were used to collect data from the respondents and participants. The Cronbach's alpha of the instrument generated was 0.717 .

\section{Measurement of Variables}

The variables of the study were measured quantitatively at the interval or ratio level using a unilinear scale. Even though, for the purpose of sequential triangulation, some of the issues were interpreted from the humanistic and qualitative point of view. This subsection focuses on describing the quantitative measurement of the variables.

Independent variables: The independent variables were personality-traits (extroversion, openness to experience, agreeableness, conscientiousness and neuroticism) and learning styles (visual, auditory, read/write and kinaesthetic) of students. Personalitytraits are the consistent traits or characteristics of an individual which make him or her different from others. Learning styles on the other hand, refers to individual difference factors that represent enduring and stable approaches to gaining, processing, and storing information for use in future. Multiple close-ended items were used to elicit data on these dimensions. Responses to the items were measured quantitatively at the interval or ratio level using a unilinear scale such that one represents the least agreement to the items while five represents the strongest agreement to the items.

Mediating variables: Academic self-discipline and self-confidence of students were the mediating variables for this study. Academic self-confidence is the belief one has that he or she can perform well in the field of academics while academic self-discipline is a behaviour that a student possesses to enable him or her become perseverance in all what it takes to be an academic abiding student. The two variables were measured using 10 close-ended items each. Numerical values were used to represents the responses to these items. They were measured using a unilinear scale.

Dependent variable: Students' academic performance, which was seen as the output or effort a student makes in the field of academics. It was measured using the CGPA of the students. The data relating to students' academic performance were secondary in nature. Just like the primary data, the secondary data were transformed from eight-point scale into five-point scale. These are: one (less than 50), two $(50-59)$, three $(60-69)$, four $(70-$ $79)$, and five $(80-100)$.

\section{Data Collection Procedure and Analysis}

A period of seven weeks was used for collecting the data. The data collection process was carried out in four stages. Stage one was the collection of list of respondents from the Students Records Management Unit of the College. Stage two was the distribution of the questionnaire and stage three was the retrieving stage. The data collection processes were carried out from one region to another and from one centre to another. The fourth stage was the interview conducted. There were 88.9 percent response rate and 92.9 percent participation rate. Data were analysed using hierarchical multiple regression analysis. This inferential statistical tool was used to determine if the potential explanatory variables and the mediating variables explained a substantial proportion of the variance in the 
overall academic performance of students. Cross case analysis was employed for the qualitative data.

\section{RESULTS AND DISCUSSION}

Using the hierarchical multiple regression analysis to test the hypothesis, a diagnostic test was first conducted to check for multicollinearity among the independent and mediating variables. The preliminary results show that the contribution of the independent and mediating variables on the dependent variable was largely not as a result of the strong association between the variables. The results of the analysis are presented in Tables 1.

The analysis involved testing of three models. In the first model, the dimensions of the two variables: personality-traits and learning styles were entered as independent variables. As depicted in the table, with the exception of neuroticism, all the entered variables in the first model that were statistically significant, contributed positively to students' academic performance. However, agreeableness was not significant in the first model.

In terms of percentage, the results further show that learning styles contributed more to students' academic performance than personality-traits. Specifically, read/write was the variable that contributed more to students' academic performance. It contributed 31.7 percent. This shows that DBE students of CoDE, UCC preference is for information displayed as words, and therefore they have a strong preference for aural/auditory learning style. This may be so because in Ghana, being able to write well and read widely are some of the cardinal attributes or conditions sought by many employers of graduates.

Table 1. Influence of Personality-Traits and Learning Styles on Students' Academic Performance

\begin{tabular}{|c|c|c|c|c|c|c|c|c|c|c|c|c|}
\hline \multirow{3}{*}{ Variables } & \multicolumn{4}{|c|}{ Model One } & \multicolumn{4}{|c|}{ Model Two } & \multicolumn{4}{|c|}{ Model Three } \\
\hline & \multicolumn{2}{|c|}{$\begin{array}{l}\text { Unstandardised } \\
\text { Coefficient }\end{array}$} & \multicolumn{2}{|c|}{$\begin{array}{l}\text { Standardised } \\
\text { Coefficient }\end{array}$} & \multicolumn{2}{|c|}{$\begin{array}{l}\text { Unstandardised } \\
\text { Coefficient }\end{array}$} & \multicolumn{2}{|c|}{$\begin{array}{c}\text { Standardised } \\
\text { Coefficient }\end{array}$} & \multicolumn{2}{|c|}{$\begin{array}{l}\text { Unstandardised } \\
\text { Coefficient }\end{array}$} & \multicolumn{2}{|c|}{$\begin{array}{l}\text { Standardised } \\
\text { Coefficient }\end{array}$} \\
\hline & B & Std. Error & Beta $(\beta)$ & Sig. & B & Std. Error & Beta $(\beta)$ & Sig. & B & Std. Error & Beta $(\beta)$ & Sig. \\
\hline Extroversion & 0.043 & 0.024 & 0.047 & 0.072 & 0.029 & 0.024 & 0.032 & 0.217 & 0.081 & 0.030 & $0.083^{*+*}$ & 0.007 \\
\hline Conscientiousness & 0.108 & 0.027 & $0.096^{* *}$ & 0.000 & 0.111 & 0.026 & $0.098^{* *}$ & 0.000 & 0.061 & 0.021 & $0.066^{* *}$ & 0.004 \\
\hline Agreeableness & -0.044 & 0.025 & -0.043 & 0.082 & 0.046 & 0.025 & 0.045 & 0.064 & 0.046 & 0.025 & $0.044^{*}$ & 0.016 \\
\hline Openness to Experience & 0.047 & 0.023 & $0.057^{*}$ & 0.047 & 0.029 & 0.023 & 0.036 & 0.208 & 0.097 & 0.046 & $0.098^{* *}$ & 0.001 \\
\hline Neuroticism & -0.068 & 0.021 & $-0.073^{*+}$ & 0.001 & -0.066 & 0.021 & $-0.072^{*}$ & 0.021 & -0.026 & 0.023 & $-0.032^{*}$ & 0.025 \\
\hline Visual & 0.089 & 0.023 & $0.100^{* *}$ & 0.000 & 0.098 & 0.022 & $0.111^{* *}$ & 0.000 & 0.222 & 0.054 & $0.242^{* *}$ & 0.000 \\
\hline Aural/Auditory & 0.063 & 0.026 & $0.063^{*}$ & 0.016 & 0.046 & 0.025 & 0.047 & 0.069 & 0.223 & 0.057 & $0.237^{* *}$ & 0.000 \\
\hline Read/Write & 0.322 & 0.021 & $0.317^{* *}$ & 0.000 & 0.283 & 0.022 & $0.278^{*+*}$ & 0.000 & 0.382 & 0.022 & $0.377^{*+}$ & 0.000 \\
\hline Kinaesthetic & 0.087 & 0.021 & $0.085^{* *}$ & 0.000 & 0.058 & 0.021 & $0.057^{* *}$ & 0.005 & 0.094 & 0.027 & $0.106^{* *}$ & 0.000 \\
\hline Academic Self-Discipline & & & & & 0.122 & 0.022 & $0.123^{*+}$ & 0.000 & 0.186 & 0.053 & $0.197^{* *}$ & 0.001 \\
\hline Academic Self-Confidence & & & & & & & & & 0.145 & 0.051 & $0.158^{* *}$ & 0.005 \\
\hline $\begin{array}{l}\text { Constant } \\
\text { R } \\
\text { R Square } \\
\text { Adjusted R Square }\end{array}$ & & $\begin{array}{l}1.06 \\
0.58 \\
0.3 \\
0.3\end{array}$ & & & & $\begin{array}{l}1.4 \\
0.6 \\
0.4 \\
0.4\end{array}$ & & & & $\begin{array}{l}0.74 \\
0.89 \\
0.79 \\
0.78\end{array}$ & & \\
\hline${ }^{* *} . p<0.01 ;{ }^{*} \cdot p<0.05$ & $(\mathrm{~N}$ & 679) & & & & & & & & & & \\
\hline
\end{tabular}


It is however significant to observe, that the total contribution of the independent variables to the variance in the dependent variable is 0.347 with an adjusted $\mathrm{R}^{2}$ of 0.336 . This means that learning styles and personality-traits are able to predict or explain 34.7 percent of the variance in students' academic performance. This also means that quite apart from the entered variables, other variables that have not yet considered in the model have a chance of contributing 65.3 percent to students' academic performance. The study therefore, introduced the moderators into the model to examine their effect.

In the second model, academic self-discipline which was the first moderating variable considered was entered into the model to examine its role. Table 1 shows that conscientiousness, neuroticism, visual, read/write, and kinaesthetic were still statistically significant when students' academic self-discipline was introduced into the first model. However, openness to experience and aural/auditory variables lost their significance level at 0.05 . Academic self-discipline $(\beta=0.123, p<0.01)$ was statistically significant when it was entered into the model. This shows that students' academic self-discipline has a significant role to play when examining the influence of personality-traits and learning styles on students' academic performance.

In the third model, the second moderating variable which was academic selfconfidence was entered into the second model to serve as a moderating factor. The assumption of the study is that the independent variables do not directly predict academic performance of DBE students of CoDE, UCC, and that they do so indirectly when students' academic self-discipline and self-confidence are considered. When academic self-confidence variable was entered into the second model as a moderating variable, the beta coefficients of all the entered variables increased. It must be pointed out that all the variables that were not statistically significant in the first and second models became statistically significant in the third model.

As indicated in Table 1 , academic self-confidence $(\beta=0.158, \mathrm{p}<0.01)$ was statistically significant when it was entered into the second model. Neuroticism still contributed negatively to academic performance. This shows that learning styles contributed more to students' academic performance than personality-traits. Furthermore, the moderating variables: academic self-discipline (19.7\%) and academic self-confidence (15.8\%) contributed meaningfully in boosting students' academic performance.

The results in Table 1 show that students' academic self-discipline and selfconfidence are significant factors that help in boosting their academic performance. The total contribution $\left(\mathrm{R}^{2}\right)$ of the variables when academic self-confidence was introduced to the second model to generate the third model increased from 0.493 to 0.797 , while the adjusted $\mathrm{R}^{2}$ increased to 0.784 . This demonstrates that when the moderating variables entered the model, the rate of increase of the $\mathrm{R}^{2}$ was 38.1 percent. This finding reinforces most researchers' arguments, that academic self-discipline and academic self-confidence are mediating variables that help in boosting the influence of personality-traits and learning styles on academic performance.

The findings imply that the various traits or characteristics that make a student different from others, and also the various enduring and stable approaches that students use in gaining, processing and storing information for future use, have a significant influence on academic performance. However, this influence can be described as indirect since the consideration of students' academic self-discipline and self-confidence enhance their academic performance significantly. The study, therefore fails to reject the hypothesis which states that students' personality-traits and learning-styles do not have a strong 
direct influence on their academic performance since there is enough evidence to prove that the influence is indirect.

The study further elicited qualitative data in order to examine the influence of personality-traits and learning styles on students' academic performance. The views of the participants were consistent with the quantitative findings. One of the centre coordinators who also double as a course tutor in one of the centres said that:

The interaction of personality-traits and learning styles can predict the academic performance in a distance education environment, especially learning styles. I think that the kind of learning style adopted by the individual student should fit his/her psychological, social and work/home demands. Students who are able to identify the kind of learning style that fit their situation are able to do well in their academic activities. Students who are able to demonstrate appropriate personality-traits and also are able to adopt a meaningful learning style, that are compatible to who they are, end up being serious in the classroom, and in their academic activities as a whole. I think that this situation can help them to possess and nurture behaviours that will enable them to become perseverance in all what it takes to be academic abiding students. This will make them not to be afraid in asking questions in class, but rather will enhance their preparation before coming to class for face-to-face interactions. This in the long run will also help them to develop a sense of academic responsibility, and the belief that they can perform well in the field of academics. I am sure that when all these are manifested will help increase the academic performance of these students. However, certain factors such as negative peer influence, financial problems, home and work pressure and family conflicts can thwart the influence of personality-traits and learning styles on students' academic performance, even if they show a high level of academic discipline and self-confidence. Furthermore, I am sure that if we as course tutors of the college are able to adopt an appropriate usage of teaching and learning materials, and other teaching methodologies such as Dalton method, field trip, demonstration in addition to the discussion, and question and answer method, will help us to satisfy all students with various personality-traits and learning styles (A Male Centre Coordinator).

The findings are in line with the comments, submissions and findings of other researchers. However, there are few ones that do not corroborate with the findings of this study. According to Aragon et al. (2012), many research findings in the social sciences, pedagogy and education, argue for the strong relationship between academic selfdiscipline and academic performance, with lack of discipline considered as a factor in declining academic performance. Academic self-discipline and self-confidence are therefore, proposed as a mediating variables between the individual's inherited abilities, their learning styles and the opportunities afforded by the academic environment of higher education.

The findings further support the comments of Rimmerman (2016) who posits that personality-traits and learning styles are good predictors of students' academic performance. The point being established is that if students perceive these variables in positive terms, it will help them in boosting their confidence level with regard to academic issues by first being academic self-disciplined. Therefore, enhancement of students' academic self-discipline through counselling programmes will in turn make them more confident of themselves with regard to their academic work which in the long run will also help improve their academic performance significantly. This means that students are to be assisted through counselling programmes to learn to be academically selfdisciplined. Besides, they must also exert some level of effort in their academic work and be conscientious to develop academically. This will no doubt boost their academic work through which will also lead to significant increase in their academic performance. 


\section{CONCLUSIONS}

From the findings of the study, the following conclusions are drawn. First, the study concludes that openness to experience trait that students demonstrate contributes more to their likelihood of obtaining high level of academic performance. This is so because they have developed the ability to entertain new ideas and think outside the box. In relation to learning styles, DBE students of the college prefer using read/write and visual learning style. However, kinaesthetic learning style was the least learning style used by the students. Also, the study can conclude that the higher the traits of an individual which make him or her different from others are demonstrated consistently, the higher he/she performs in his/her academic activity. Similarly, whenever the individual difference factors that represent enduring and stable approaches to gaining, processing, and storing information are high, the academic performance of the student will also move in the same direction.

Lastly, the study concludes that the various traits, that make a student different from others, and also the various enduring and stable approaches that students use in gaining, processing and storing information have a significant influence on students' academic performance. However, this influence can be described as indirect because when students begin to believe that they can perform well in the field of academics, and also behave in a way that make them become perseverance in all what it takes them to be academic abiding students, then their adopted personality-traits and learning styles will influence their academic performance significantly.

\section{REFERENCES}

Abidin, J. Z., Rezaee, A. L., Abdullah, H. N., \& Singh, K. K. B. (2011). Learning styles and overall academic achievement in a specific educational system. International Journal of Humanities and Social Science, 1(10), 143-152.

Akrofi, D. (2010). Distance education at the University of Education, Winneba: Challenges and prospects. Unpublished master's thesis, Faculty of Education, University of Cape Coast, Cape Coast.

Aragon, S. R., Johnson, S. D., \& Shaik, N. (2012). The influence of learning style preferences, mediated by academic discipline and self-confident, on student success in online versus face-to-face environments. American Journal of Distance Education, 26 (4), 227-244.

Ary, D., Jacobs, L. C., Sorensen, C., \& Razavich, A. (2010). Introduction to research in education (8th ed.). Belmont: Wadsworth, Cengage Learning.

Busari, A. O. (2017). The relationship between personality types, learning styles, motivation, self-esteem and academic stress among distance learners at Ibadan study centre. International Journal of Innovation and Applied Studies, 19 (4), 850-862. 
College of Distance Education [CoDE] University of Cape Coast [UCC] (2017a). Draft report on students' academic performance by students' records unit. Unpublished report, CoDE, Cape Coast.

College of Distance Education [CoDE] University of Cape Coast [UCC] (2017b). The 49th congregation for CoDE: 2017. Retrieved July 23, 2017, from https://code.ucc.edu. gh/notice/49th-congregation-code-2017.

Irani, T., Telg, R., Scherler, C., \& Harrington, M. (2012). Personality type and its relationship to distance education students' course perceptions and performance. The Quarterly Review of Distance Education, 13(4), 445-453.

Jannatul-Firdaos, F. (2014). Student perceptions as distance learners in Internet-based courses: The case of University of Ghana students. Unpublished master's thesis, University of Ghana, Lagon.

Koomson, A. K. (2006). Distance education as a strategy for training teachers in Ghana: Problems and prospects. Journal of the Institute of Education, 4(1), 59-68.

Rimmerman, S. L. (2016). Personality types and learning styles: An investigation of their influence on performance in a distance education environment. Unpublished doctoral dissertation, Department of Instructional and Performance Technology, College of Professional Studies, The University of West Florida, Florida.

University of Cape Coast [UCC]. (2016). Vice chancellor's annual report: To the $49^{\text {th }}$ congregation. Cape Coast: University Press. 